\title{
Pengukuran Ketepatan Alignment Sistem Penjejak Gerak Benda Langit dengan Metode Drift Berbantuan Tracker
}

\author{
Lukmanul Hakim, Yudhiakto Pramudya* \\ Magister Pendidikan Fisika, Universitas Ahmad Dahlan \\ *E-mail: yudhiakto.pramudya@pfis.uad.ac.id
}

\begin{abstract}
Abstrak
Simulasi pengunaan metode drift dengan menggunakan alat penjejak benda langit. Eksperimen dilakukan dengan merekam pergerakan alat penjejak benda langit dengan variasi arah sudut polar dan azimuth dari arah selatan dan polar azimuth sesungguhnya di tempat tertentu. Variasi antara $-2^{\circ}$ to $+2^{\circ}$. Didapatkan bahwa semakin besar perbedaan arah mounting dengan arah sesungguhnya, maka semakin besar pula pergeseran altitude dan azimuth lintasan objek langit
\end{abstract}

Kata kunci: Teleskop, Mounting, Drift, Azimuth, Altitude.

\begin{abstract}
The simulation of the drift method application using a celestial body tracker has been done. Experiments were carried out by recording the movement of a celestial body tracker with variation orientation of polar angle and azimuth from the true south and polar angle a particular location. The variation is between $-2^{\circ}$ to $+2^{\circ}$. It was found that the greater the difference in the mounting orientation from the true orientation, the greater the shift in altitude and azimuth of the celestial object's path.
\end{abstract}

Keywords: Telescope, Mounting, Drift, Azimuth, Altitude.

\section{PENDAHULUAN}

Alam semesta adalah perwujudan dari bukti adanya tuhan sebagai penciptanya. Begitu banyak misteri alam semesta mengenai penciptaannya. Penelitian - penelitian telah dilakukan agar dapat menjelaskan misteri misteri tersebut. Akan tetapi tidak semua dari misteri tersebut yang dapat dijelaskan oleh para peneliti. Salah satu cabang ilmu yang mempelajari alam semesta yaitu astronomi (Amrozi \& Amiranti, 2012). Astronomi merupakan ilmu yang mempelajari tentang benda langit (Saputra, 2018) dan menurut (Handhita et al., 2016) Astronomi merupakan cabang ilmu yang mempelajari benda-benda langit di luar atmosfer.

Pada pengamatan benda langit, tidak semua benda langit dapat dilihat dengan mata telanjang. Hal ini disebabkan karena kecerlangan atau terang sebuah obyek langit yang di pancarkan berbeda-beda. Kecerlangan atau terang suatu obyek benda dilangit dinyatakan dalam besaran yang disebut magnitudo. Magnitudo adalah tingkat kecemerlangan suatu bintang. Skala magnitudo berbanding terbalik dengan kecemerlangan bintang, artinya makin terang suatu bintang makin kecil skala magnitudonya (Gautama, 2010).

Sekitar tahun 1830, William Herschel berkesimpulan bahwa bintang yang magnitudonya 1 terangnya 100 kali lebih terang daripada bintang yang bermagnitudo 6 . Pada 1854, Norman Pogson menempatkan skala magnitudo secara kuantitatif dengan mendefinisikan perbedaan besarnya lima (antara 1 dan 6 besaran) (Riswanto \& Suseno, 2015).

Keterbatasan mata dalam melihat objek yang memiliki magnitudo tinggi dapat diatasi dengan menggunakan teleskop. Teleskop merupakan salah satu alat yang dapat digunakan untuk melihat benda pada jarak jauh. (Latief et al., 2014). Teleskop memiliki beberapa jenis yaitu teleskop refraktor dan reflektor (Kunjaya, 2014).

Teleskop adalah instrumen pengamatan 
yang berfungsi mengumpulkan cahaya dan sekaligus berfungsi untuk melihat benda-benda yang jauh agar dapat terlihat lebih dekat dan lebih jelas.(Ishaq et al., 2012). Hal ini sejalan dengan pendapat (Irvan \& Hermawan, 2019) menyatakan bahwa teleskop merupakan instrumen pengamatan yang berfungsi mengumpulkan radiasi elektromagnetik. Selain itu, teleskop membentuk citra dari bentuk yang diamati. Teleskop memperbesar ukuran sudut benda dan kecerahannya. Teleskop memiliki fungsi utama yaitu: 1) Untuk mengumpulkan cahaya sebanyak mungkin dari sebuah objek 2) Sifat terpenting teleskop adalah kekuatan pengumpulan cahaya teleskop. Semakin besar diameter obyektif teleskop, semakin banyak pula cahaya yang terkumpul.

Karena benda langit bergerak dengan kedudukan yang tetap dan bergeser secara teratur setiap hari. maka teleskop diberikan sebuah alat yang dapat mengikuti pergerakan langit itu yang dikenal dengan mounting. Mounting teleskop atau yang lebih familiar dikenal dengan "dudukan teleskop" terbagi dalam 2 jenis yaitu jenis mounting equatorial dan jenis mounting altazimuth. Mounting Equatorial bekerja menggunakan 3 buah sumbu yaitu sumbu Right Ascension, Deklinasi, dan Equator. Sedang mounting altazimuth menggunakan 2 buah sumbu yaitu sumbu $X$ atau altitude (atas bawah) dan $Y$ atau azimuth (kanan kiri) (Rahman et al., 2017).

Namun, terkadang pengamat mengalami masalah dalam melakukan pengamatan benda langit. Diantara masalah yang sering dialami oleh para pengamat yaitu kurang akuratnya sebuah teleskop dalam mengikuti pergerakan benda langit, hal ini dapat mengakibatkan hasil data citra benda langit kurang baik. Kurang akuratnya teleskop ini dalam mengikuti pergerakan benda langit pada dasarnya disebabkan pada saat pengkalibrasian teleskop yang kurang tepat sehingga sumbu perputaran mounting dengan sumbu perputaran benda langit tidak sejajar. Ada berbagi metode untuk mengatasi tidak sejajarnya sumbu perputaran mounting dengan sumbu perputaran benda langit, diantaranya adalah metode Pattern Matching. Permasalahan pada penggunaan metode Pattern Matching adalah ukuran field of view gambar dari teleskop yang sudah disejajarkan dan gambar dari teleskop yang sedang di-setup harus sama. Hal ini akan membutuhkan waktu dikarenakan untuk memperoleh field of view yang sama harus memiliki alat yang digunakan untuk mengambil data yang sama (Azzam et al., 2004).

Metode drift adalah metode yang dilakukan oleh seorang pengamat untuk memperbaiki kesalahan sebuah teleskop ketika digunakan untuk mengamati benda langit. Teleskop tersebut tidak mampu mengikuti pergerakan benda langit dengan akurat karena ketidaksejajarannya sumbu perputaran benda langit dengan sumbu perputaran mounting. Dengan melihat pergeseran pergerakan teleskop maka dapat diketahui pergerakan benda langit. Dengan metode ini, pengamat tidak memerlukan perbandingan gambar karena penggunaan metode ini dapat menggunakan hanya satu bintang. Selain itu, perbaikan kurang akuratnya alignment teleskop tidak membutuhkan waktu yang lama (Barrett, 2016b).

Penelitian ini bertujuan untuk memudahkan para peneliti memperbaiki teleskop yang dipakai karena teleskop kurang mampu mengikuti pergerakan benda langit. Hal ini dilakukan dengan mensimulasikan penggunaan metode drift dengan menggunakan sebuah alat penjejak benda langit yang telah diletakkan sebuah laser.

\section{METODE/EKSPERIMEN}

Metode penelitian ini bertempat di Kampus 2 Universitas Ahmad Dahlan dengan menggunakan metode eksperimen. Penelitian ini menggunakan peralatan sebagai berikut:

a. Laptop Windows 7 pro 64 bit RAM 4 GB, merupakan saran mengolah data menggunakan software tracker dan mendapatkan data penelitian yang diperoleh.

b. Alat penjejak benda langit, merupakan bagian yang berperan penting dalam penelitian yang berfungsi sebagai simulasi pergerakan benda langit.

c. Laser berfungsi agar mempermudah 
dalam pengambilan data dan menganalisis data menggunakan software tracker.

d. Layar berwarna putih berfungsi sebagai bidang laser diarahkan.

e. Kamera video merupakan bagian yang berperan penting dalam penelitian untuk merekam pergerakan laser yang digerakkan oleh alat penjejak langit.

f. Software tracker merupakan software yang berfungsi sebagai pengolah data yang berupa video - video

Penelitian ini mengikuti prosedur penelitian sebagai berikut:

A. Prosedur Penelitian

1. Rangkaian alat

a. Alat penjejak langit, layar, dan kamera video disusun dengan posisi seperti gambar 1.

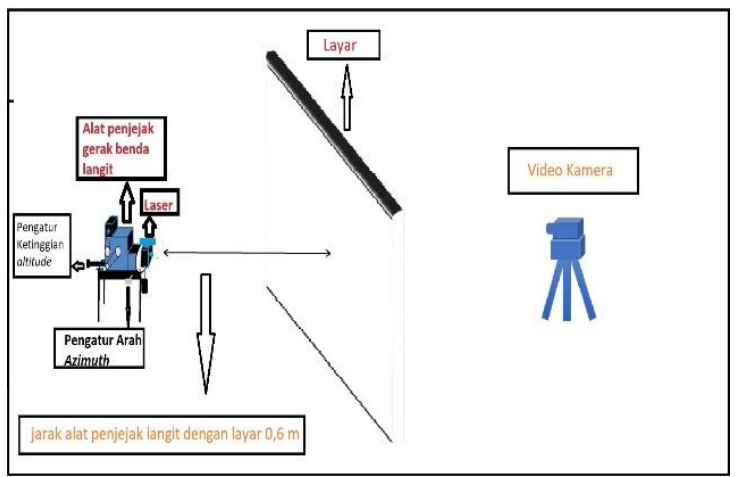

Gambar 1. Posisi alat penjejak langit, layar, dan kamera video

\section{Proses pengambilan data}

Pada penelitian ini dianggap ketinggian polar yang sesungguhnya yaitu $7^{\circ}$ dan arah azimuth polar sesungguhnya adalah $180^{\circ}$. Pengambilan data dilakukan dengan merekam pergerakan penjejak benda langit yang telah diletakkan laser dengan menggunakan kamera video pada posisi altitude pada arah azimuth dan arah azimuth pada arah pada ketinggian alttitude pada alat penjejak langit.

\section{Analisis data}

a. Setelah data berupa video didapatkan kemudian dianalisis menggunakan software tracker. Video yang telah dianalisis menggunakan software tracker terlihat seperti gambar 2 .

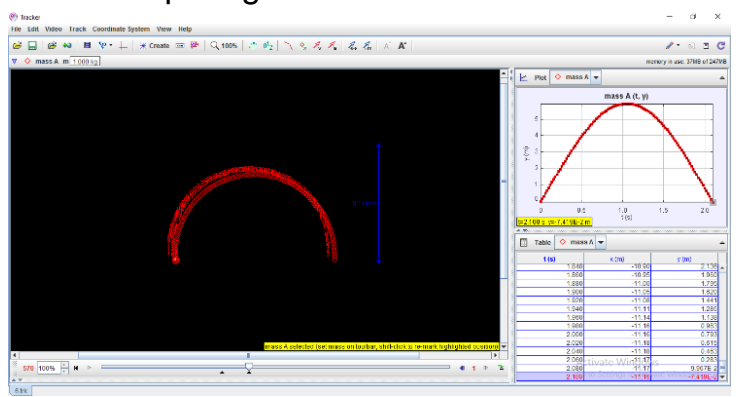

Gambar 2. Video yang telah dianalisis menggunakan software tracker.

b. Setelah video diproses dengan software tracker data yang dihasilkan diolah kembali menggunakan excel untuk memproleh nilai ketinggian polar tracker dan arah azimuth polar tracker. Nilai ketinggian polar tracker dianggap sebagai nilai ketinggian polar dan nilai arah azimuth polar tracker dianggap sebagai nilai arah azimuth polar.

\section{HASIL DAN PEMBAHASAN}

Penelitian ini bertempat di Kampus 2 Universitas Ahmad Dahlan dengan menggunakan perangkat laptop Windows 7 pro 64 bit RAM 4 GB, Alat penjejak benda langit, laser, layar yang terbuat dari kain berwarna putih dengan ukuran $1 \times 1$ meter, kamera video, dan software tracker. Alat dirangkai dengan meletakkan laser pada alat penjejak langit. Kemudian alat penjejak langit dipetakan di depan layar dengan jarak 0,6 meter. Selanjutnya, kamera diletakkan di belakang layar seperti pada gambar 1 .

(a)

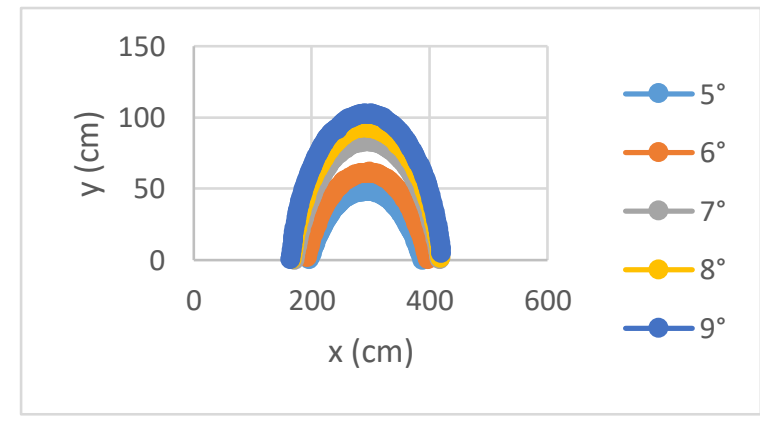


(b)

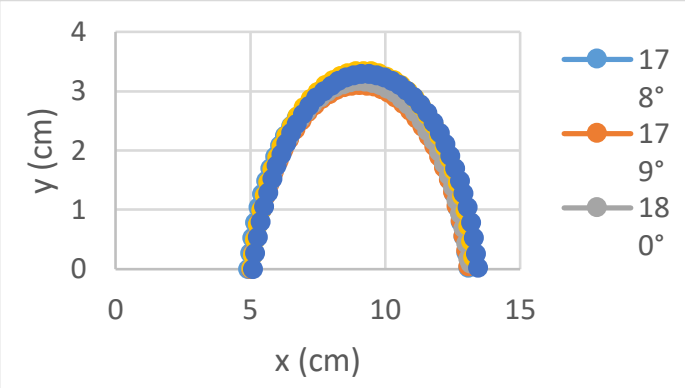

Gambar 3. Grafik dengan variasi arah (a) altitude (b) azimuth.

Sesuai dengan penggunaan metode drift untuk memperbaiki kesalahan kurang akuratnya sebuah mounting teleskop dalam mengikuti pergerakan benda langit perbaikan dilakukan dengan dengan mengatur ketinggian polar dan arah azimuth pada mounting teleskop hingga tepat sesuai dengan ketinggian polar dan arah azimuth yang sesunggunya (Barrett, 2016). Untuk mengetahui perbedaan ketinggian polar dan arah azimuth yang tepat dan ketinggian polar dan arah azimuth yang salah maka dilakukan pengambilan data dengan merekam pergerakan alat penjejak benda langit dengan variasi ketinggian polar dan arah azimuth dengan variasi antara $-2^{\circ}$ to $+2^{\circ}$.

Setelah semua video diproses dengan software tracker kemudian data diolah kembali menggunakan Excel. Selanjutnya setiap data yang telah didapatkan disatukan ke dalam satu data yang berupa bentuk grafik. Hal ini bertujuan untuk melihat perbedaan lintasan yang disebabkan ketinggian alttitude dan arah azimuth pada alat penjejak langit yang berbeda-beda. Gambar 3a untuk grafik variasi ketinggian altitude dan gambar $3 \mathrm{~b}$ untuk grafik variasi arah azimuth.

Sudut azimuth dan sudut altitude dihitung berdasarkan posisi titik di setiap lintasan pada Gambar 3a dan Gambar 3b sesuai dengan didapatkan dengan persamaan

$$
\theta=\tan y / r
$$

dengan $\theta$ adalah sudut azimuth dan sudut altitude dan $y$ adalah posisi data pada sumbu $y$. Sedangkan nilai $r$ didapatkan dengan persamaan

$$
r=\sqrt{a^{2}+b^{2}}
$$

dengan $a$ merupakan nilai yang didapatkan dengan mengurangi nilai tengah pada data $x$ dengan setiap data $x$ dan $b$ merupakan jarak alat penjejak langit dari layar.

Nilai selisih ketinggian polar dan arah azimuth polar didapatkan dengan memilih salah satu nilai dari setiap ketinggian polar tracker dan setiap arah azimuth polar pada posisi yang sama. Nilai ketinggian tersebut diubah dalam bentuk sudut. Pada penelitian ini, nilai yang dipilih pada posisi tertinggi atau pada nilai $y$ yang paling tinggi. Pemilihan pada posisi ini dikarenakan untuk mempermudah pemilihan posisi yang sama di setiap data. Kemudian setiap data tersebut dikurangi dengan data ketinggian polar tracker dan arah azimuth polar tracker yang sebenarnya. Hasil dari data tersebut untuk selisih ketinggian altitude dapat dilihat pada tabel 1 dan hasil data untuk selisih arah azimuth polar dapat dilihat pada tabel 2 .

Tabel 1. Selisih Ketinggian Altitude

\begin{tabular}{cccc}
\hline \multicolumn{2}{c}{ Altitude } & \multicolumn{2}{c}{ Selisih } \\
\hline $\begin{array}{c}\text { Altitude } \\
\text { Penjejak } \\
\text { Langit }\end{array}$ & $\begin{array}{c}\text { Altitude } \\
\text { Tracker }\end{array}$ & $\begin{array}{c}\text { Altitude } \\
\text { Penjejak } \\
\text { langit }\end{array}$ & $\begin{array}{c}\text { Altitude } \\
\text { Tracker }\end{array}$ \\
\hline $5^{0}$ & $89,04^{0}$ & $2^{0}$ & $0,34^{0}$ \\
$6^{0}$ & $89,23^{0}$ & $1^{0}$ & $0,15^{0}$ \\
$7^{0}$ & $89,39^{0}$ & $0^{0}$ & $0,00^{0}$ \\
$8^{0}$ & $89,42^{0}$ & $-1^{0}$ & $-0,04^{0}$ \\
$9^{0}$ & $89,47^{0}$ & $-2^{0}$ & $-0,08^{0}$
\end{tabular}

Tabel 2. Selisih Arah Polar Azimuth

\begin{tabular}{cccc}
\hline \multicolumn{2}{c}{ Azimuth } & \multicolumn{2}{c}{ Selisih } \\
\hline $\begin{array}{c}\text { Azimuth } \\
\text { Penjejak } \\
\text { Langit }\end{array}$ & $\begin{array}{c}\text { Azimuth } \\
\text { Tracker }\end{array}$ & $\begin{array}{c}\text { Azimuth } \\
\text { Penjejak } \\
\text { langit }\end{array}$ & $\begin{array}{c}\text { Azimuth } \\
\text { Tracker }\end{array}$ \\
\hline $178^{0}$ & $78,40^{0}$ & $2^{0}$ & $0,87^{0}$ \\
$179^{0}$ & $79,03^{0}$ & $1^{0}$ & $0,24^{0}$ \\
$180^{0}$ & $79,27^{0}$ & $0^{0}$ & $0,00^{0}$ \\
$181^{0}$ & $79,79^{0}$ & $-1^{0}$ & $-0,52^{0}$ \\
$182^{0}$ & $79,64^{0}$ & $-2^{0}$ & $-0,37^{0}$
\end{tabular}




\section{PENUTUP}

Selisih ketinggian polar dari $-2^{\circ}$ sampai $+2^{\circ}$ dari ketinggian altitude polar yang sesungguhnya yaitu $7^{\circ}$ didapatkan bahwa semakin besar jarak selisih dari ketinggian polar dari ketinggian polar yang sesungguhnya maka semakin besar pula pergeseran ketinggian polarnya dan arah azimuth. Untuk selisih arah azimuth-nya dari $-2^{\circ}$ sampai $+2^{\circ}$ dari arah azimuth yang sesungguhnya yaitu $180^{\circ}$ didapatkan bahwa semakin besar jarak selisih arah azimuth polar maka semakin besar pula pergeseran arah azimuth dari arah azimuth yang sesungguhnya.

\section{REFERENSI}

Amrozi, M., \& Amiranti, S. (2012). Perancangan Museum Astronomi Bertema Paradoks (Big Bang) Sebagai Pusat Informasi Perbintangan di Indonesia. Jurnal Sains Dan Seni ITS, 1(1), 59-64.

http://ejurnal.its.ac.id/index.php/sains_seni/art icle/view/2133

Azzam, Y. A., Kosuge, K., Wang, Z., Alawy, A. A., \& $Y$ Hirata. (2004). Telescope Automatic Alignment and Pointing using Pattern Matching. The Fourth International Conference on the Advanced Mechatronics, 96-102.

Barrett, F. (2016a). Determining Polar Axis Alignment Accuracy (2nd Edition (ed.); pp. 111).

Barrett, F. (2016b). Measuring Polar Axis Alignment Error (3rd Edition (ed.); pp. 1-12).

Gautama, S. E. (2010). Astronomi Dan Astrofisika (Revisi Ke-3). SMA Negeri 1 Makasar.

Handhita, E. T., Akhlis, I., \& Marwanto, P. (2016). Pengembangan Media Pembelajaran Materi Astronomi Berbasis Visual Novel Ren'Py. Unnes Physics Education Journal, 5(2), 3541. https://doi.org/10.15294/upej.v5i2.13617

Irvan, \& Hermawan, L. (2019). Mengenal Jenis-Jenis Teleskop dan Penggunaannya. Al-Marshad: Jurnal Astronomi Islam Dan IImu-IImu Berkaitan, 5(1), 74-89. https://doi.org/10.30596/jam.v5i1.3125

Ishaq, U. M., Supatmi, S., Mustika, M. E., \& Komputer, J. T. (2012). Pengendalian Sudut Pada Pergerakan Teleskop Refraktor Menggunakan Personal Computer. Jurnal Sistem Komputer Unikom, 1(1), 38-43. https://ojs.unikom.ac.id/index.php/komputika/ article/view/116

Kunjaya, C. (2014). Suplemen ASTROFISIKA untuk SMA. PT.Trisula Adisakti.

Latief, M. B., Muchlas, \& Pramudya, Y. (2014). Sistem pelacak otomatis gerakan benda langit pada teleskop refraktor berbasis mikrokontroler. Jurnal Fisika Indonesia, XVIII(54), 82-85. https://journal.ugm.ac.id/jif/article/view/24378/ 15870

Rahman, A. A., Rivai, M., \& Tasripan. (2017). Sistem Otomatisasi Pelacakan Objek Astronomi Menggunakan Teleskop Berdasarkan Stellarium. Jurnal Teknik ITS, 6(2), 539-543. https://doi.org/10.12962/j23373539.v6i2.2412 1

Riswanto, \& Suseno, N. (2015). Dasar-Dasar Astronomi Dan Fisika Kebumian. Lembaga Penelitian UM Metro Press.

Saputra, O. (2018). Revolusi dalam Perkembangan Astronomi: Hilangnya Pluto Dalam Keanggotaan Planet Pada Sistem Tata Surya. Jurnal Filsafat Indonesia, 1(1), 71-74. https://doi.org/10.23887/jfi.v1i2.13992 